\title{
Antioxidant, Anti-Inflammatory and Anti-Angiogenic Properties of Citrus lumia Juice
}

\author{
Antonella Smeriglio, Marcella Denaro, Valeria D'Angelo, Maria Paola Germanò and \\ Domenico Trombetta*
}

Department of Chemical, Biological, Pharmaceutical and Environmental Sciences, University of Messina, Messina, Italy

\section{OPEN ACCESS}

Edited by:

Rosa Tundis,

University of Calabria, Italy

Reviewed by:

Silvana Morello,

University of Salerno, Italy Roberta d'Emmanuele di Villa Bianca, University of Naples Federico II, Italy

*Correspondence:

Domenico Trombetta trombetta@unime.it

Specialty section:

This article was submitted to Cardiovascular and Smooth Muscle Pharmacology, a section of the journal

Frontiers in Pharmacology

Received: 10 August 2020 Accepted: 09 November 2020 Published: 03 December 2020

Citation: Smeriglio A, Denaro M, D'Angelo V, Germanò MP and Trombetta D (2020) Antioxidant, Anti-Inflammatory and Anti-Angiogenic Properties of Citrus

lumia Juice.

Front. Pharmacol. 11:593506. doi: 10.3389/fphar.2020.593506
Citrus juices are a rich source of bioactive compounds with various and well-known health benefits. The aim of this study was to investigate the polyphenols and ascorbic acid content as well as to investigate the antioxidant, anti-inflammatory and anti-angiogenic properties of the juice of an ancient Mediterranean species, Citrus lumia Risso (CLJ). The antioxidant and anti-inflammatory activities were evaluated by several in vitro cell-free and cell-based assays, whereas two different in vivo models, the chick chorioallantoic membrane (CAM) and the zebrafish embryos, were used to characterize the anti-angiogenic properties. Twenty-eight polyphenols were identified by RP-LC-DAD-ESI-MS analysis (flavonoids $68.82 \%$ and phenolic acids 31.18\%) with 1-caffeoyl-5-feruloylquinic acid and kaempferol 3'rhamnoside, which represent the most abundant compounds (25.70 and $23.12 \%$, respectively). HPLC-DAD analysis showed a high ascorbic acid content $(352 \mathrm{mg} / \mathrm{kg}$ of CLJ), which contributes with polyphenols to the marked and dose-dependent antioxidant and anti-inflammatory properties observed. CLJ showed strong and dose-dependent antiangiogenic activity as highlighted by the inhibition of blood vessel formation on CAMs and the decrease of endogenous alkaline phosphatase on zebrafish embryos. Moreover, within the concentration range tested, no dead or malformed embryos were recorded. Certainly, further studies are needed to investigate the molecular mechanisms underlying these promising biological effects, but considering the evidence of the present study, the use of CLJ as a ready-to drink safe prevention strategy for inflammatory-based diseases correlated to angiogenesis could be justified.

Keywords: citrus juice, antioxidant, anti-inflammatory, anti-angiogenic, polyphenols, ascorbic acid, chick chorioallantoic membrane, zebrafish embryos

\section{INTRODUCTION}

Given the changes occurring in lifestyle and the growing evidences, which suggest a direct correlation between Mediterranean diet and improved health, international guidelines for health promotion and disease prevention recommend to consume mainly functional foods such as fruits and vegetables (Slavin and Lloyd, 2012). However, despite there is a global consensus about the protective role of fruits and vegetables, there is no clear evidence about the effects of consuming the fruit juices (Hyson, 2015), because their lower fiber content and higher caloric density in comparison with the fresh fruits. On the contrary, it has been demonstrated that fruit juices without additives such as the sweeteners, labelled by FDA as 100\% Citrus juice, retain the majority of nutrients as well as of other non-nutrients bioactive compounds of the parent fruit such as ascorbic acid and polyphenols, well-known for their health effects (Hyson, 2015). 
Citrus juices are widely distributed and commonly consumed beverages worldwide, because Citrus fruits are easy to find and "ready to drink", providing a natural balance of water, vitamins, minerals, sugars, carotenoids, fiber and organic acids, together with a pleasant and fresh flavour (Hyson, 2015).

Moreover, Citrus juice have been identified as one of the most promising sources of flavonoids in the human diet, compounds well-known for their antioxidant, cytoprotective, anti-angiogenic, anti-inflammatory and anti-cancer properties (Barreca et al., 2017; Cirmi et al., 2017).

Several studies have established that diet, along with early screening, play a pivotal role in the management of several inflammation-based diseases, suggesting that prevention starts from what we eat and what we drink (Rossi et al., 2014). However, the translation of in vitro and in vivo results on clinic scenario still represents a difficult obstacle to overcome.

Despite the unfavourable weather has led to smaller crops in the last year in several countries, current worldwide production of Citrus fruits settles around 92 million tons, with the oranges which represent alone about the half of the total production, followed by tangerines/mandarins, grapefruits and lemons/limes (United States Department of Agriculture, 2020a). However, Citrus crops are not limited to mainstream species, because this genus is fairly variegated and constantly evolving, comprising several species, varieties, cultivars and hybrids (Barreca et al., 2020). Only a small part of this production is assigned to the fresh market, while the other part is mainly addressed to make fresh juices, Citrus-based drinks, marmalades, jelly and flavouring ingredients (Smeriglio et al., 2018a).

Recently, we have focused our attention on an ancient Mediterranean Citrus fruit, Citrus lumia Risso, (Smeriglio et al., 2018a; Smeriglio et al., 2019a). The chemical composition, and the antioxidant, anti-cholinesterase, and neuroactive properties of its essential oil were investigated, showing marked antioxidant and neuroactive effects, paving the way for its potential application in the field of oxidativebased neurodegenerative diseases (Smeriglio et al., 2018a). Moreover, the extract of $C$. lumia albedo revealed marked antioxidant and free radical scavenging properties as well as significant cytoprotective activity on tert-butyl hydroperoxidetreated lymphocytes, suggesting that this by-product is a valuable source for nutraceutical employment (Smeriglio et al., 2019a).

Considering this, the aim of the present study has been to investigate for the first time the chemical features, in particular the polyphenol profile and the ascorbic acid content, of fresh $C$. lumia juice, focusing on the evaluation of its antioxidant, antiinflammatory and anti-angiogenic properties.

\section{MATERIALS AND METHODS}

\section{Chemicals}

The Folin-Ciocalteu reagent, sodium carbonate $\left(\mathrm{Na}_{2} \mathrm{CO}_{3}\right)$, aluminium chloride $\left(\mathrm{AlCl}_{3}\right)$, sodium nitrite $\left(\mathrm{NaNO}_{2}\right)$, sodium hydroxide $(\mathrm{NaOH}), \quad m$-phosphoric acid, 1,1-diphenyl-2picrylhydrazyl (DPPH), 2,20-azino-bis(3-ethylbenzothiazoline-6sulfonic acid (ABTS), potassium persulfate $\left(\mathrm{K}_{2} \mathrm{~S}_{2} \mathrm{O}_{8}\right)$, 6-hydroxy- 2,5,7,8-tetramethylchromane-2-carboxylic acid (Trolox), 2,2' azobis(2-methylpropionamidine) dihydrochloride (AAPH), fluorescein sodium salt, sodium phosphate dibasic $\left(\mathrm{Na}_{2} \mathrm{HPO}_{4}\right)$, potassium phosphate monobasic $\left(\mathrm{KH}_{2} \mathrm{PO}_{4}\right), 2,4,6$-tris(2-pyridyl)S-triazine (TPTZ), iron sulphate heptahydrate $\left(\mathrm{FeSO}_{4} \bullet 7 \mathrm{H}_{2} \mathrm{O}\right)$, sodium acetate $\left(\mathrm{CH}_{3} \mathrm{COONa}\right)$, bovine serum albumin (BSA) heat shock fraction protease, fatty acid and essentially globulin free $(\mathrm{pH} 7$, $\geq 98 \%$ ), trypsine from porcine pancreas Type IX-S lyophilized powder (13,000-20,000 BAEE units/mg protein), perchloric acid, trizma-base, retinoic acid, diethanolamine, $p$-nitrophenyl phosphate disodium salt, ethylenediaminetetraacetic acid (EDTA), butylated hydroxytoluene (BHT), diclofenac sodium, lipopolysaccharides from Escherichia coli O55:B5, 2',7'-dichlorofluorescein diacetate (DCF-DA), hydrogen peroxide, Histopaque ${ }^{\circledR}-1077$, RPMI-1640 with L-glutamine, penicillin-streptomycin solution, fetal bovine serum and trypan blue were purchased from Sigma-Aldrich (MSt. Louis, MO, United States). Acetonitrile, trifluoroacetic acid and formic acid were HPLC grade and were purchased, as well as L-ascorbic acid solution $1.0 \mathrm{mg} / \mathrm{ml}$ in acetonitrile:water, certified reference material Cerilliant ${ }^{\circledR}$ and DMSO, from Merck (Darmstadt, Germany).

\section{Plant Material and Sample Preparation}

Fresh fruits of C. lumia Risso were harvested in March 2019 by a local farmer in Agrigento (Sicily, Italy). C. lumia Risso juice (CLJ) was obtained by a manually juice processor and centrifuged at $3500 \times \mathrm{g}\left(\right.$ Neya 10R, REMI, Mumbai, India) for $15 \mathrm{~min}$ at $4^{\circ} \mathrm{C}$. The supernatant, which density at $20^{\circ} \mathrm{C}$ is $1.011 \mathrm{~g} / \mathrm{cm}^{3}$, was collected and stored at $-80^{\circ} \mathrm{C}$ until use. CLJ was properly diluted in deionized water before in vitro and in vivo analyses, whereas for HPLC analysis CLJ was diluted in MilliQ water and filtered by a $0.22 \mu \mathrm{m}$ nylon syringe filter.

\section{Total Phenols Content}

Total phenols were determined according to Smeriglio et al. (2018b). Fifty microliters of sample solution (6.33-50.6 $\mu \mathrm{l} /$ $6.25-50 \mathrm{mg} / \mathrm{ml}$ of CLJ diluted in deionized water) or gallic acid as reference compound $(75-600 \mu \mathrm{g} / \mathrm{ml})$, were added to Folin-Ciocalteu $(500 \mu \mathrm{l})$ and deionized water $(450 \mu \mathrm{l})$ and incubated for $3 \mathrm{~min}$. After that, $50 \mu \mathrm{l}$ of $10 \% \mathrm{Na}_{2} \mathrm{CO}_{3} w / v$ were added to the mixture and samples were left in dark at RT for $60 \mathrm{~min}$, mixing every $10 \mathrm{~min}$. The absorbance was read at $785 \mathrm{~nm}$ against a blank consisting of deionized water instead of sample by using an UV-Vis spectrophotometer (Shimadzu UV 1601, Kyoto, Japan). Results were expressed as milligrams of gallic acid equivalents (GAE)/100 g of CLJ.

\section{Total Flavonoids Content}

Total flavonoids were determined according to Bazzicalupo et al. (2019) with some modifications. Briefly, $450 \mu \mathrm{l}$ of deionized water were added with $50 \mu \mathrm{l}$ of sample $(6.33-50.6 \mu \mathrm{l} / 6.25-50 \mathrm{mg} / \mathrm{ml}$ of CLJ diluted in deionized water) or rutin as reference compound $(125-1000 \mu \mathrm{g} / \mathrm{ml})$, mixed with $30 \mu \mathrm{l}$ of $5 \% \mathrm{NaNO}_{2}$ and incubated for $5 \mathrm{~min}$. After that, $60 \mu \mathrm{l}$ of $10 \% \mathrm{AlCl}_{3}$ were added to the mixture and incubated for $6 \mathrm{~min}$. Then, $0.2 \mathrm{~mL}$ of sodium hydroxide $(1 \mathrm{M})$ and $210 \mu \mathrm{l}$ of deionized water were added and the absorbance was recorded at $510 \mathrm{~nm}$ against a blank 
consisting of deionized water instead of sample by an UV-Vis spectrophotometer (Shimadzu UV-1601, Kyoto, Japan). Results were expressed as milligrams of rutin equivalents (RE)/100 g of CLJ.

\section{Ascorbic Acid Determination}

The determination of ascorbic acid content was carried out according to Mazurek and Jamroz (2015) with some modifications. A sample solution consisting of CLJ and $2 \%$ $m$-phosphoric acid $(1: 1 v / v)$, shielded from light in order to prevent the loss of ascorbic acid, was filtered through a 0.22 $\mu \mathrm{m}$ nylon syringe filter and injected into a high performance liquid chromatography system equipped with a photodiode-array detector (HPLC-DAD, Agilent technologies, Santa Clara, CA, United States). The chromatographic separation was performed by a $5 \mu \mathrm{m}$ Eclipse plus column $(150 \times 4.6 \mathrm{~mm}$; Phenomenex, Torrance, CA, United States) maintained at $25^{\circ} \mathrm{C}$ using $0.025 \%$ trifluoroacetic acid solution as mobile phase. Flow rate and injection volume were $0.8 \mathrm{ml} / \mathrm{min}$ and $20 \mu \mathrm{l}$, respectively. UVVis spectra were acquired in the range $190-400 \mathrm{~nm}$, whereas the acquisition of chromatograms was carried out at $254 \mathrm{~nm}$. The peak identity was confirmed by comparing the retention time and UV-Vis spectra of sample with pure ( $\geq 99 \%$ ) commercially available ascorbic acid standard. Quantification was carried out by an external standard calibration curve (concentration range $0.625-5 \mu \mathrm{g} / \mathrm{ml})$.

\section{Polyphenols Characterization}

The polyphenols characterization was carried out by a reversedphase liquid chromatography coupled with diode array detection and electrospray ion trap mass spectrometry (RP-LC-DAD-ESIMS) analysis. At this purpose a Luna Omega PS C18 column (150 $\times 2.1 \mathrm{~mm}, 5 \mu \mathrm{m}$; Phenomenex, Torrance, CA, United States) at room temperature (RT) and with a flow rate of $0.4 \mathrm{~mL} / \mathrm{min}$ was used. The mobile phase and elution program was the same reported in Smeriglio et al. (2018b). The injection volume was $5 \mu \mathrm{l}$. The UV-Vis spectra were recorded in the $190-600 \mathrm{~nm}$ range and chromatograms were acquired at different wavelength (260, 292, 330 and $370 \mathrm{~nm}$ ) to identified all polyphenol classes. The experimental parameters of the mass spectrometer (ion trap, Agilent model 6320) operating in both positive (ESI+) and negative (ESI-) ionization mode were set as follows: the capillary voltage was $3.5 \mathrm{kV}$, the nebulizer $\left(\mathrm{N}_{2}\right)$ pressure was $40 \mathrm{psi}$, the drying gas temperature was $350^{\circ} \mathrm{C}$, the drying gas flow was $9 \mathrm{~L} / \mathrm{min}$ and the skimmer voltage was $40 \mathrm{~V}$. The mass spectrometer was operated in full-scan mode in the $\mathrm{m} / \mathrm{z}$ range 90-1000. Data were acquired by Agilent ChemStation version B.01.03 and Software Trap control version 6.2.

\section{In Vitro Cell-free Assays Antioxidant Activity}

The antioxidant activity of CLJ was evaluated by several in vitro assays, based on different mechanisms (electron, hydrogen or electron and hydrogen transfer-based assays) and reaction environments. Results, obtained by three independent experiments in triplicate $(n=3)$ were expressed as inhibition percentage $(\%)$ of the oxidative/radical activity, calculating the half-maximal inhibitory concentration $\left(\mathrm{IC}_{50}\right)$ with the respective confident limits (C.L.) at $95 \%$. All concentration ranges following reported refer to final volumes/concentrations of CLJ and reference compounds in the reaction mixture.

\section{DPPH Assay}

The scavenging activity against the DPPH radical was evaluated according to Smeriglio et al. (2017). Briefly, $37.5 \mu \mathrm{l}$ of CLJ diluted in deionized water $(0.030-0.243 \mu \mathrm{l} / 30.0-240.0 \mu \mathrm{g} / \mathrm{ml})$ or trolox as reference compound $(0.625-5.0 \mu \mathrm{g} / \mathrm{ml})$ were added to fresh $10^{-4} \mathrm{M}$ DPPH methanol solution $(1.5 \mathrm{ml})$, mixed and incubated in the dark for $20 \mathrm{~min}$. The decrease in absorbance was recorded at $517 \mathrm{~nm}$ against a blank consisting of deionized water instead of sample by using an UV-Vis spectrophotometer (Shimadzu UV-1601, Kyoto, Japan).

\section{Trolox Equivalent Antioxidant Capacity (TEAC)}

The scavenging activity against the ABTS radical was evaluated according to Monforte et al. (2018). Briefly, the radical solution was prepared by mixing $4.3 \mathrm{mM} \mathrm{K}_{2} \mathrm{~S}_{2} \mathrm{O}_{8}$ and $1.7 \mathrm{mM}$ ABTS (1:5, $v / v)$ and incubating for 12 hours in dark at RT. The reaction mixture was then diluted with deionized water (absorbance of $0.7 \pm 0.02)$ and used within 4 hours. Fifty microliters of CLJ diluted in deionized water $(0.005-0.040 \mu \mathrm{l} / 5.0-40.0 \mu \mathrm{g} / \mathrm{ml})$ or trolox as reference compound $(0.625-5.0 \mu \mathrm{g} / \mathrm{ml})$ were added to $1 \mathrm{ml}$ of the reagent and incubated at RT for $6 \mathrm{~min}$. The absorbance was recorded at $734 \mathrm{~nm}$ against a blank consisting of deionized water instead of sample by an UV-Vis spectrophotometer (Shimadzu UV-1601, Kyoto, Japan).

\section{Ferric Reducing Antioxidant Power (FRAP)}

The FRAP assay was carried out according to Smeriglio et al. (2019b). Fifty microliters of CLJ diluted in deionized water $(0.08-0.65 \mu \mathrm{l} / 80.0-640.0 \mu \mathrm{g} / \mathrm{ml})$ or trolox as reference compound $(1.25-10.0 \mu \mathrm{g} / \mathrm{ml})$ were added to freshly and prewarmed $\left(37^{\circ} \mathrm{C}\right)$ working FRAP reagent $(1.5 \mathrm{ml})$. After $4 \mathrm{~min}$ of incubation at RT in the dark, the absorbance was recorded at $593 \mathrm{~nm}$ by an UV-Vis spectrophotometer (Shimadzu UV-1601, Kyoto, Japan) against a blank consisting of deionized water instead of sample.

\section{Oxygen Radical Absorbance Capacity (ORAC)}

The ORAC assay was carried out according to Smeriglio et al. (2019c). Briefly, $20 \mu \mathrm{l}$ of several CLJ dilutions (0.002-0.016 $\mu \mathrm{l} /$ $2.0-16.0 \mu \mathrm{g} / \mathrm{ml})$, trolox as reference compound $(0.25-2.5 \mu \mathrm{g} / \mathrm{ml})$ or deionized water as blank were added to $120 \mu \mathrm{l}$ of $117 \mathrm{nM}$ fluorescein solution. After an incubation time of $15 \mathrm{~min}$ at $37^{\circ} \mathrm{C}$, $60 \mu \mathrm{l}$ of $40 \mathrm{mM}$ AAPH were added to each well starting the reaction, which was monitored every $30 \mathrm{~s}$ for $90 \min \left(\lambda_{\text {ex }} 485 \mathrm{~nm}\right.$; $\lambda_{\mathrm{em}} 520 \mathrm{~nm}$ ) by a fluorescence plate reader (FLUOstar Omega, BMG LABTECH, Ortenberg, Germany).

\section{Iron-Chelating Activity}

The ferrozine assay was carried out according to Smeriglio et al. (2019c). Fifty microliters of $2 \mathrm{mM} \mathrm{FeCl} \cdot 4 \mathrm{H}_{2} \mathrm{O}$ solution were added in $100 \mu \mathrm{l}$ of CLJ sample diluted in deionized water $(0.05-0.40 \mu \mathrm{l} / 50.0-400.0 \mu \mathrm{g} / \mathrm{ml})$, EDTA $(1.5-12 \mu \mathrm{g} / \mathrm{ml})$ as 
reference compound or deionized water as blank and incubated at RT for $5 \mathrm{~min}$. Then, $100 \mu \mathrm{l}$ of $5 \mathrm{mM}$ ferrozine solution and $3 \mathrm{ml}$ of deionized water were added to the mixture and incubated for $10 \mathrm{~min}$ at RT. The absorbance was read at $562 \mathrm{~nm}$ by an UV-Vis spectrophotometer (Shimadzu UV-1601, Kyoto, Japan).

\section{$\beta$-Carotene Bleaching}

The test was carried out using an emulsion prepared according to Barreca et al. (2016). Eight milliliters of fresh emulsion were mixed with $0.23 \mu \mathrm{l}$ of CLJ samples diluted in deionized water $(0.10-0.81 \mu \mathrm{l} / 100.0-800.0 \mu \mathrm{g} / \mathrm{ml})$, BHT $(0.031-0.25 \mu \mathrm{g} / \mathrm{ml})$ as reference compound or deionized water as blank. A $\beta$-carotene-free emulsion was used as negative control. The mixture was initially measured at $470 \mathrm{~nm}(t=0)$, by an UVVis spectrophotometer (Shimadzu UV-1601, Kyoto, Japan) and then incubated in a water bath $\left(50^{\circ} \mathrm{C}\right)$ for $120 \mathrm{~min}$, recording the absorbance every $20 \mathrm{~min}$.

\section{Anti-Inflammatory Activities \\ Bovine Serum Albumin Denaturation Assay}

This assay, which evaluates the inhibitory activity of CLJ on BSAheath induced-denaturation, was carried out according to Saso et al. (2001). Briefly, $100 \mu \mathrm{l}$ of $0.4 \%$ fatty free BSA solution and $20 \mu \mathrm{l}$ of phosphate buffered saline (PBS, $\mathrm{pH}$ 5.3) were added to $80 \mu \mathrm{l}$ of CLJ samples diluted in deionized water $(0.40-3.24 \mu \mathrm{l} /$ $0.40-3.20 \mathrm{mg} / \mathrm{ml})$. The solution was read initially $(t=0)$ and after an incubation time of $30 \mathrm{~min}(t=30)$ at $70^{\circ} \mathrm{C}$, recording the absorbance at $595 \mathrm{~nm}$ by a plate reader (Multiskan GO; Thermo Scientific, MA, United States). A blank with deionized water instead of sample was used as negative control. The antiinflammatory power was expressed as inhibition (\%) of albumin denaturation (ID), and it was calculated as follows:

$$
\% I D=\left(\frac{(1-(A-B))}{(C-B)}\right) \times 100
$$

where $\mathrm{A}=$ sample absorbance at $t=30 ; \mathrm{B}=$ blank absorbance at $t=0$; $C=$ blank absorbance at $t=30$.

The $\mathrm{IC}_{50}$ with the respective C.L. at $95 \%$ was calculated.

\section{Anti-protease Activity}

The anti-tryptic activity of CLJ was evaluated according to Oyedapo and Famurewa (1995). Briefly, $200 \mu \mathrm{l}$ of several CLJ samples diluted in deionized water $(0.06-0.51 \mu \mathrm{l} / 63.0-500.0 \mu \mathrm{g} /$ $\mathrm{ml}$ ) were added to the reaction mixture consisting of $12 \mu \mathrm{l}$ of trypsin $(10 \mu \mathrm{g} / \mathrm{ml})$ and $188 \mu \mathrm{l}$ of $25 \mathrm{mM}$ Tris-HCl buffer ( $\mathrm{pH} 7.5)$, both diluted in deionized water. After that, $200 \mu \mathrm{l}$ of $0.8 \%$ casein were added and the reaction mixture was incubated for $20 \mathrm{~min}$ at $37^{\circ} \mathrm{C}$ in a water bath. At the end of the incubation time, $400 \mu \mathrm{l}$ of perchloric acid were added to stop the reaction and to allow the protein precipitation. The cloudy suspension was centrifuged at $3500 \times \mathrm{g}$ for $10 \mathrm{~min}$ and the absorbance of the supernatant was recorded at $280 \mathrm{~nm}$ against a blank consisting of deionized water instead of sample, using an UV-Vis spectrophotometer (Shimadzu UV-1601, Kyoto, Japan). Diclofenac sodium $(20.0-80.0 \mu \mathrm{g} / \mathrm{ml})$ was used as reference compound. Results, obtained by three independent experiments in triplicate $(n=$
3) were expressed as inhibition percentage (\%) of the protease activity, calculating the $\mathrm{IC}_{50}$ with the respective C.L. at $95 \%$.

\section{In Vitro Cell-Based Assays}

Overnight fasting (12 hours) venous blood samples from 10 healthy donors chosen according to specific inclusion (signed informed consent, males and females, aged between 23 and 40 years, non-smokers) and exclusion criteria (history of drug abuse including alcohol, participation in experimental trials within 3 months prior to study, use of any kind of drugs within the previous 3 months, pathologies) were collected in heparinized tubes.

\section{Preparation of Erythrocytes Suspension}

Erythrocytes suspension was prepared according to Gunathilake et al. (2018). Briefly, the fresh blood samples were centrifuged at $2400 \times \mathrm{g}$ for $5 \mathrm{~min}$ and the erythrocytes layer washed three times 1:1 $(v / v)$ with saline solution $(0.9 \% \quad \mathrm{NaCl})$. After the centrifugation, the packed erythrocytes were suspended at 10 and $1 \%(v / v)$ with $10 \mathrm{mM}$ sodium phosphate buffer $\mathrm{pH} 7.4$ (PBS) for heat-induced hemolysis and free radical scavenging activity against intracellular reactive oxygen species (ROS) assays, respectively.

\section{Heat-Induced Hemolysis Assay}

According to Gunathilake et al. (2018), $0.05 \mathrm{ml}$ of $10 \%$ erythrocytes suspension and $0.05 \mathrm{ml}$ of several CLJ samples diluted in PBS $(0.21-0.82 \mu \mathrm{l} / 200.0-800.0 \mu \mathrm{g} / \mathrm{ml})$, diclofenac sodium $50-200 \mu \mathrm{g} / \mathrm{ml}$ (positive control) or phosphate buffer (negative control) were added to $2.95 \mathrm{ml}$ of PBS. The mixture was incubated at $54^{\circ} \mathrm{C}$ for $20 \mathrm{~min}$ in a water bath and then centrifuged at $2000 \times \mathrm{g}$ for $3 \mathrm{~min}$. The absorbance of the supernatant was recorded at $540 \mathrm{~nm}$ using an UV-Vis Spectrophotometer (Shimadzu UV-1601, Kyoto, Japan) and the level of hemolysis was calculated using the following equation:

$$
\% \text { hemolysis inhibition }=100 \times(1-A s / A c)
$$

where $A s$ is the absorbance of the test sample and $A c$ is the absorbance of the negative control.

\section{Free-Radical Scavenging Activity Against Intracellular ROS} The free-radical scavenging activity of CLJ against the intracellular ROS was evaluated according to Widen et al. (2012) with some modifications. Briefly, $0.01 \mathrm{ml}$ of CLJ samples diluted in PBS $(0.03-0.10 \mu \mathrm{l} / 25.0-100.0 \mu \mathrm{g} / \mathrm{ml})$, trolox $12.5-50 \mu \mathrm{g} /$ $\mathrm{ml}$ (positive control) or PBS (negative control) were added to $1 \mathrm{ml}$ of $1 \%$ erythrocytes suspension, mixed and incubated in the dark for $2 \mathrm{~h}$ at $20^{\circ} \mathrm{C}$ under constant agitation $(120 \mathrm{rpm})$ using an Innova 4000 benchtop incubator shaker (New Brunswick Scientific, NJ, United States). The erythrocytes were washed three times in PBS 1:1 $(v / v)$ and centrifuged at $2400 \times \mathrm{g}$ for $5 \mathrm{~min}$ in order to remove any extracellular trace of antioxidant compounds. The cell pellet was lysed by the addition of distilled water $(0.1 \mathrm{ml})$ and $1 \mathrm{ml}$ of DCF-DA working solution in PBS $(0.28 \mu \mathrm{g} / \mathrm{ml})$ was added. After this, $18.9 \mu \mathrm{l}$ of $30 \%$ $\mathrm{H}_{2} \mathrm{O}_{2}(167 \mathrm{mM})$ was added and the degree of ROS release monitored by recording the fluorescence intensity after $10 \min \left(\lambda_{\text {ex }} 485 ; \lambda_{\text {em }} 535\right)$. 
Peripheral Blood Mononuclear Cell (PBMC) Isolation PBMC isolation was carried out according to Viji and Helen (2008). Briefly, Histopaque 1.077 was placed in a $15 \mathrm{ml}$ tube and whole blood was stratified on the top. After the centrifugation $\left(400 \times \mathrm{g}\right.$ for $30 \mathrm{~min}$ at $20^{\circ} \mathrm{C}$, with $9 / 3$ acceleration/deceleration ramp), the PBMC were carefully recovered from the buffy coat and washed three times with PBS. The pellet was resuspended in culture medium consisting of RPMI 1640 supplemented with $2 \mathrm{mM}$ L-glutamine, 10\% FBS and 1\% penicillin/streptomycin and cell concentration brought to $1 \times 10^{6}$ cells $/ \mathrm{ml}$. Cell viability was assessed by trypan blue staining under the microscope.

\section{Anti-inflammatory Activity}

The anti-inflammatory activity of CLJ was evaluated according to Hougee et al. (2005) with some modifications. Briefly, freshly PBMC suspension $(150 \mu \mathrm{l})$ were seeded in a 96-wells cell culture plate (Nunc ${ }^{\circledR}$, Merck, Darmstadt, Germany). Twenty microliters of CLJ samples diluted in PBS $(0.26-1.03 \mu \mathrm{l} / 0.25-1.0 \mathrm{mg} / \mathrm{ml})$, diclofenac sodium $12.5-50 \mu \mathrm{g} / \mathrm{ml}$ (positive control) or PBS (negative control) were added and cells were incubated for $1 \mathrm{~h}$ at $37^{\circ} \mathrm{C}, 5 \% \mathrm{CO}_{2}$. After that, inflammation was induced by adding $30 \mu \mathrm{l}$ of LPS $(10 \mathrm{ng} / \mathrm{ml})$ in each well, incubating for another $16 \mathrm{~h}$ at $37^{\circ} \mathrm{C}, 5 \% \mathrm{CO}_{2}$.

Cell supernatants were harvested and interleukin-6 (IL-6) and tumor necrosis factor $\alpha$ (TNF- $\alpha$ ) release was measured by highsensitivity human ELISA kits (DRG Diagnostics $\mathrm{GmbH}$, Marburg, Germany) according to the manufacturer's recommendations.

\section{In Vivo Evaluation of the Anti-angiogenic Properties Chick Chorioallantoic Membrane (CAM) Assay}

The evaluation of the anti-angiogenic properties of CLJ was carried out according to Smeriglio et al. (2019d). Briefly, fertilized eggs of Gallus gallus were incubated for 4 days in a humidified incubator at $37^{\circ} \mathrm{C}$, in order to favour the vessels growth and the CAM development. Eggs, which showed malformed or dead embryos were discarded. The CLJ samples diluted in deionized water $(0.09-0.71 \mu \mathrm{l} / 90.0-700.0 \mu \mathrm{g} / \mathrm{ml})$, retinoic acid $(10 \mu \mathrm{g} / \mathrm{ml})$ as positive control or deionized water as negative control were applied directly on the CAM surfaces and eggs were incubated for $24 \mathrm{~h}$. The anti-angiogenic effect was evaluated by counting the blood vessel branch points in a standardized area by a stereomicroscope (SMZ-171 Series, Motic, Hong Kong, China) equipped with a digital camera (Moticam $^{\circledast} 5$ plus). Images were processed by the GNU Image Manipulation Program (GIMP version 2.10.2).

Results, obtained by three independent experiments in quintuplicate $(n=5)$ were expressed as inhibition percentage (\%) of the angiogenic activity, calculating the $\mathrm{IC}_{50}$ with the respective C.L. at $95 \%$.

\section{Endogenous Alkaline Phosphatase (EAP) Activity on Zebrafish Embryos}

The quantification of EAP in zebrafish (Danio rerio, Hamilton) embryos was carried out according to Iannuzzi et al. (2019) following the ethical guidelines described by National Institute of Health Guide for Care and Use of Laboratory Animals.

Briefly, several male and female zebrafish specimens were purchased by a local pet store and kept in an aquarium at $28^{\circ} \mathrm{C}$ with $14 / 10$ (light/dark) photoperiod. After a natural mating, embryos were generated and cultured in water at $28.5^{\circ} \mathrm{C}$. Twenty-four hours post-fertilization (hpf), the healthy and regular ones were selected. After dechorionizing, embryos were distributed in a 96-well plate and incubated with $100 \mu \mathrm{l}$ of embryos water containing different volumes/concentrations of CLJ $(0.13-0.51 \mu \mathrm{l} / 125.0-500.0 \mu \mathrm{g} / \mathrm{ml})$ or reference standard 2methoxyestradiol (2-ME, $30 \mu \mathrm{g} / \mathrm{ml})$. Deionized water was used as negative control. All embryos were incubated for $72 \mathrm{hpf}$. After that, embryos were dehydrated by using increasing concentrations of ethanol, washed three time with $1 \mathrm{M}$ diethanolamine buffer ( $\mathrm{pH}$ 9.8) and then incubated for 30 min at RT with $p$-nitrophenyl phosphate disodium salt (substrate). At the end of incubation time, $2 \mathrm{M} \mathrm{NaOH}$ was added to stop the reaction. The absorbance of soluble EAP was recorded at $405 \mathrm{~nm}$ by a microplate reader (Multiskan GO; Thermo Scientific, MA, United States).

Results, obtained by three independent experiments in quintuplicate $(n=5)$, were expressed as inhibition percentage (\%) of the EAP activity, calculating the $\mathrm{IC}_{50}$ with the respective C.L. at $95 \%$.

\section{Statistical Analysis}

Results were expressed as the average \pm standard deviation (S.D.) of three independent experiments in triplicate $(n=3)$ for in vitro cellfree and cell-based experiments and of three independent experiments in quintuplicate $(n=5)$ for in vivo experiments. The statistical significance was evaluated by one-way analysis of variance (ANOVA) followed by Tukey's test using SigmaPlot 12.0 software. Data were considered statistically significant for $p<0.05$.

\section{RESULTS}

\section{Phytochemical Analyses}

This study investigates for the first time the polyphenol profile and the biological activity of CLJ. Preliminary phytochemical screening using in vitro colorimetric tests revealed a high content of total phenols $(819.05 \pm 37.68 \mathrm{mg} \mathrm{GAE} / 100 \mathrm{~g}$ of CLJ) as well as a very high content of flavonoids ( $1054.40 \mathrm{mg} \mathrm{RE} / 100 \mathrm{~g}$ of CLJ). These preliminary data were confirmed by the determination of the polyphenol profile by RP-LC-DAD-ESI-MS analysis, which allowed to identify 28 polyphenols belonging to 6 different classes. The predominant class is that of flavonols $(43.37 \%)$ followed by hydroxycinnamic acids (29.68\%), flavones (14.84\%), flavanones (9.40\%), hydroxybenzoic acids (1.50\%) and isoflavones $(0.15 \%)$ (Figure 1; Table 1).

Table 1 shows the identified polyphenols classified according to the class they belong to and their relative abundance (mean area percentage) at $330 \mathrm{~nm}$, wavelength at which it is possible to detect all compounds identified. The peak numbers refer to the elution order as shown in Figure 1. As can be seen from the representative chromatogram shown in Figure 1, the method 


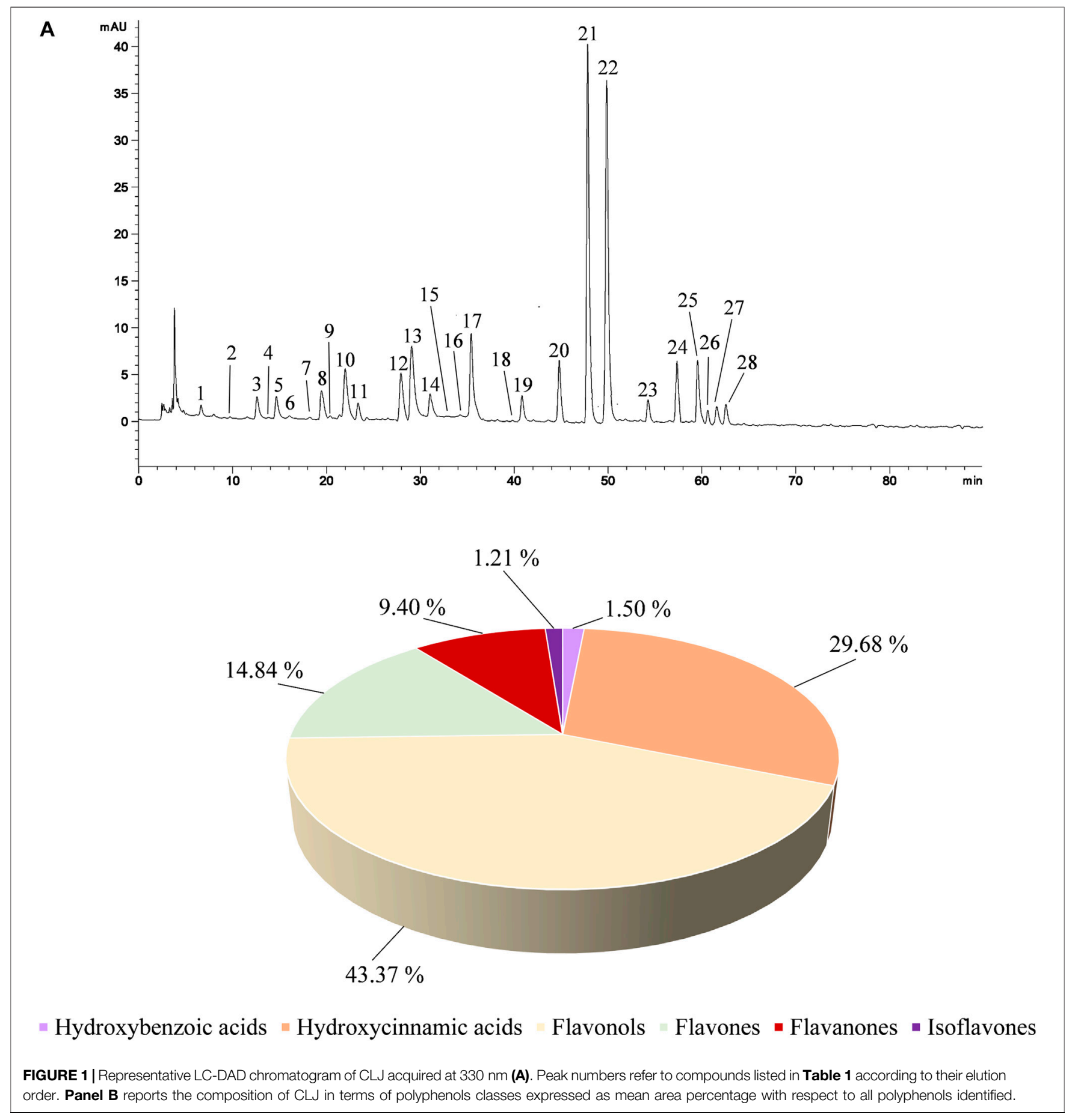

used allowed to separate all compounds without any base-line interference or co-elution.

Since CLJ is an aqueous matrix, the polyphenol profile is mostly made up of glycosylated derivatives of both phenolic acids and flavonoids. The predominant compound is 1-caffeoyl-5feruloylquinic acid belonging to the class of hydroxycinnamic acids, which represents the $25.70 \%$ of the identified polyphenols. Among the flavonoids, the predominant compound is kaempferol $3^{\prime}$-rhamnoside (23.12\%) followed by diosmetin-6-
$C$-b- $D$-glucoside (9.35\%), quercetin 3-O-(6“-malonyl-glucoside) (7.72\%), quercetin 3-(2"-p-hydroxybenzoyl-4"-p-coumarylrhamnoside) (6.77\%), neohesperidin dihydrochalcone (4.51\%) and dihydroquercetin 3-O-rhamnoside (4.41\%) (Table 1).

Since Citrus juices are generally rich in vitamin $C$, the ascorbic acid content was determined by HPLC-DAD analysis, revealing that CLJ is a rich source of this metabolite $(352 \mathrm{mg} / \mathrm{kg}$ of CLJ) that is well known as well as polyphenols for its marked anti-oxidant, anti-inflammatory and anti-angiogenic properties. 
TABLE 1 | Characterization of the polyphenol profile of $C$. lumia juice by RP-LC-DAD-ESI-MS analysis.

\begin{tabular}{|c|c|c|c|c|c|c|}
\hline Peak no. & Compound & RT & Area $\%$ & $\lambda_{\max }$ & $m / z$ & {$[\mathrm{M}-\mathrm{H}]^{-} /[\mathrm{M}-\mathrm{H}]^{+}$} \\
\hline \multicolumn{7}{|c|}{ Hydroxybenzoic acids } \\
\hline 5 & 1,1'-biphenyl, 4-Hydroxybenzoic acid & 14.70 & $1.50 \pm 0.08$ & 306 & 292 & $/ 293$ \\
\hline \multicolumn{7}{|c|}{ Hydroxycinnamic acids } \\
\hline 2 & Feruloyl-O-sinapoyl-O-caffeoylquinic acid & 9.61 & $0.07 \pm 0.00$ & 280 & 736 & $735 / 737$ \\
\hline 3 & (E)-3-(3,4-diacetoxy-5-methoxyphenyl)-acroyl-4-O-p-Coumaroyl-5-O-Caffeoylquinic acid & 12.59 & $1.69 \pm 0.02$ & 302 & 778 & $777 /$ \\
\hline 7 & Caffeoylquinate shikmate derivative & 18.14 & $0.13 \pm 0.01$ & 270 & 510 & $509 / 511$ \\
\hline 18 & 1-Sinapoyl-2-feruloylgentiobiose & 39.74 & $1.31 \pm 0.06$ & $282 ; 350$ & 724 & $723 / 725$ \\
\hline 22 & 1-Caffeoyl-5-feruloylquinic acid & 49.80 & $25.70 \pm 1.55$ & $284 ; 336$ & 530 & $531 / 529$ \\
\hline 26 & 3,4-Dicaffeoylquinic acid & 60.66 & $0.78 \pm 0.01$ & 280; 336 & 516 & $515 /$ \\
\hline \multicolumn{7}{|l|}{ Flavonols } \\
\hline 4 & Kaempferol 3,7,4'-O-triglucoside & 13.79 & $0.07 \pm 0.00$ & 304 & 772 & $771 / 773$ \\
\hline 8 & Limocitrol-O-glucoside & 18.79 & $0.23 \pm 0.00$ & $286 ; 328$ & 538 & $537 / 539$ \\
\hline 17 & Quercetin 3-(2"'-p-hydroxybenzoyl-4"'-p-Coumarylrhamnoside) & 35.47 & $6.77 \pm 0.15$ & 290; 330 & 714 & 713/ \\
\hline 19 & Quercetin 3-O-(6"-malonyl-glucoside)-7-O-glucoside & 40.62 & $0.11 \pm 0.01$ & $282 ; 350$ & 712 & $711 / 713$ \\
\hline 21 & Kaempferol $3^{\prime}$ - rhamnoside & 47.80 & $23.12 \pm 0.84$ & $272 ; 348$ & 432 & $431 / 432$ \\
\hline 24 & Quercetin 3-O-(6"-malonyl-glucoside) & 57.68 & $7.72 \pm 0.38$ & 280; 336 & 550 & $549 / 551$ \\
\hline 25 & Dihydroquercetin 3-O-rhamnoside & 59.54 & $4.41 \pm 0.18$ & $284 ; 316$ & 449 & $448 / 450$ \\
\hline 28 & Isorhamnetin 3(7)-O-glucuronopyranosyl-(1-2)-O-glucuronopyranoside & 62.62 & $0.94 \pm 0.04$ & $284 ; 326$ & 668 & $669 / 667$ \\
\hline \multicolumn{7}{|c|}{ 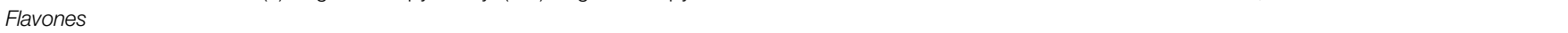 } \\
\hline 1 & Apigenin 7-O-glucuronide & 6.61 & $0.57 \pm 0.02$ & $280 ; 300$ & 446 & $445 / 447$ \\
\hline 9 & Apigenina-7-O-glucoside & 19.47 & $1.56 \pm 0.03$ & $280 ; 328$ & 432 & $431 / 433$ \\
\hline 6 & Myricetin 3-O-galactoside & 15.83 & $0.08 \pm 0.00$ & 274 & 480 & $479 / 481$ \\
\hline 13 & Diosmetin-6-C-b-D-glucoside & 29.43 & $9.35 \pm 0.25$ & 260; 300 & 462 & $461 / 463$ \\
\hline 14 & Diosmetin 6,8-di-C-glucoside & 30.85 & $2.04 \pm 0.08$ & 260; 300 & 624 & $623 / 625$ \\
\hline 23 & Tricin 7-O-[glucuronopyranosyl-(1-2)-O-methyloglucuronopyranoside] & 54.54 & $0.10 \pm 0.01$ & $276 ; 336 ; 370$ & 696 & $695 / 697$ \\
\hline 27 & Orientin-sulphate & 61.56 & $1.14 \pm 0.07$ & $280 ; 336 ; 370$ & 528 & $527 / 529$ \\
\hline \multicolumn{7}{|c|}{ Flavanones } \\
\hline 10 & Neohesperidin dihydrochalcone & 21.96 & $4.51 \pm 0.08$ & 260; 296 & 612 & $611 / 613$ \\
\hline 11 & Naringenin-7-O-glucoside & 23.34 & $1.19 \pm 0.03$ & $284 ; 325 ; 370$ & 433 & $432 / 434$ \\
\hline 15 & Neoeriocitrin & 32.89 & $0.05 \pm 0.00$ & 286; 326 & 596 & $595 / 597$ \\
\hline 16 & Neohesperidin & 34.35 & $1.68 \pm 0.06$ & $274 ; 334$ & 610 & $609 / 611$ \\
\hline 12 & 5,7-dihydroxy-49-methoxyflavanone 7-O-Neohesperidoside & 28.57 & $1.97 \pm 0.03$ & $280 ; 330$ & 594 & $593 / 595$ \\
\hline \multicolumn{7}{|c|}{ Isoflavones } \\
\hline 20 & 6"-O-Malonyl daidzin & 45.81 & $1.21 \pm 0.05$ & 280; 338 & 502 & $501 / 503$ \\
\hline
\end{tabular}

Results were expressed as mean area percentage \pm standard deviation $(\mathrm{n}=3$ ) of each compound with respect to the total area of polyphenols identified. Bold numbers refer to the most abundant compounds.

\section{Antioxidant and Anti-inflammatory Properties}

The antioxidant and free-radical scavenging properties of CLJ were tested firstly by several in vitro colorimetric assays based on different environments and reaction mechanisms as well as against differently charged radicals. CLJ showed a strong and dose-dependent $\left(R^{2} \geq 0.9181\right)$ antioxidant and free radicalscavenging activity with the following order of potency: ORAC > TEAC $>\beta$-carotene bleaching $>$ DPPH $>$ FRAP $>$ Iron-chelating activity (Figure 2).

Table 2 shows the $\mathrm{IC}_{50}$ values $(\mu \mathrm{g} / \mathrm{ml})$ of CLJ in comparison with those of the reference standards trolox and BHT.

Despite there is a statistically significant difference $(p<0.01)$ in comparison with the reference compounds, it is necessary to underline that CLJ has been tested simply diluted in deionized water, therefore we are talking about a food as it is, and not of a polyphenol extract. Considering this, CLJ has proven to be a plant complex with a very strong antioxidant and free-radical scavenging activity, because these activities are translatable, in vitro, considering the density of the juice reported in the Total Phenols Content, to a few microliters of fresh juice $(\sim 0.002-0.243 \mu \mathrm{l})$.
Preliminary screening of the anti-inflammatory activity of a plant complex can be evaluated in vitro by two simple colorimetric assays, the BSA denaturation assay and the antiprotease activity test.

Anti-inflammatory drugs act by protecting endogenous proteins against denaturation (Saso et al., 2001). At this purpose, the effect of CLJ on heat-induced BSA denaturation was evaluated in comparison with the anti-inflammatory drug diclofenac sodium as positive control (Figure 3A).

CLJ showed a strong anti-inflammatory activity by inhibiting, in statistically significant $(p<0.01)$ and dose-dependent manner $\left(R^{2}=0.9763\right)$, the heat-induced BSA denaturation. Moreover, the highest concentration tested $(3.20 \mathrm{mg} / \mathrm{ml}$ equal to $\sim 3 \mu \mathrm{l}$ of CLJ) showed the best anti-inflammatory activity (77.35\%) in comparison with the positive control diclofenac sodium $50 \mu \mathrm{g} /$ $\mathrm{ml}(60.51 \%)$.

The anti-tryptic activity of CLJ was investigated, as antiinflammatory marker, considering that proteases have been implicated in several inflammatory-based diseases promoting the tumorigenesis and invasive growth (Oyedapo and Famurewa, 1995). 

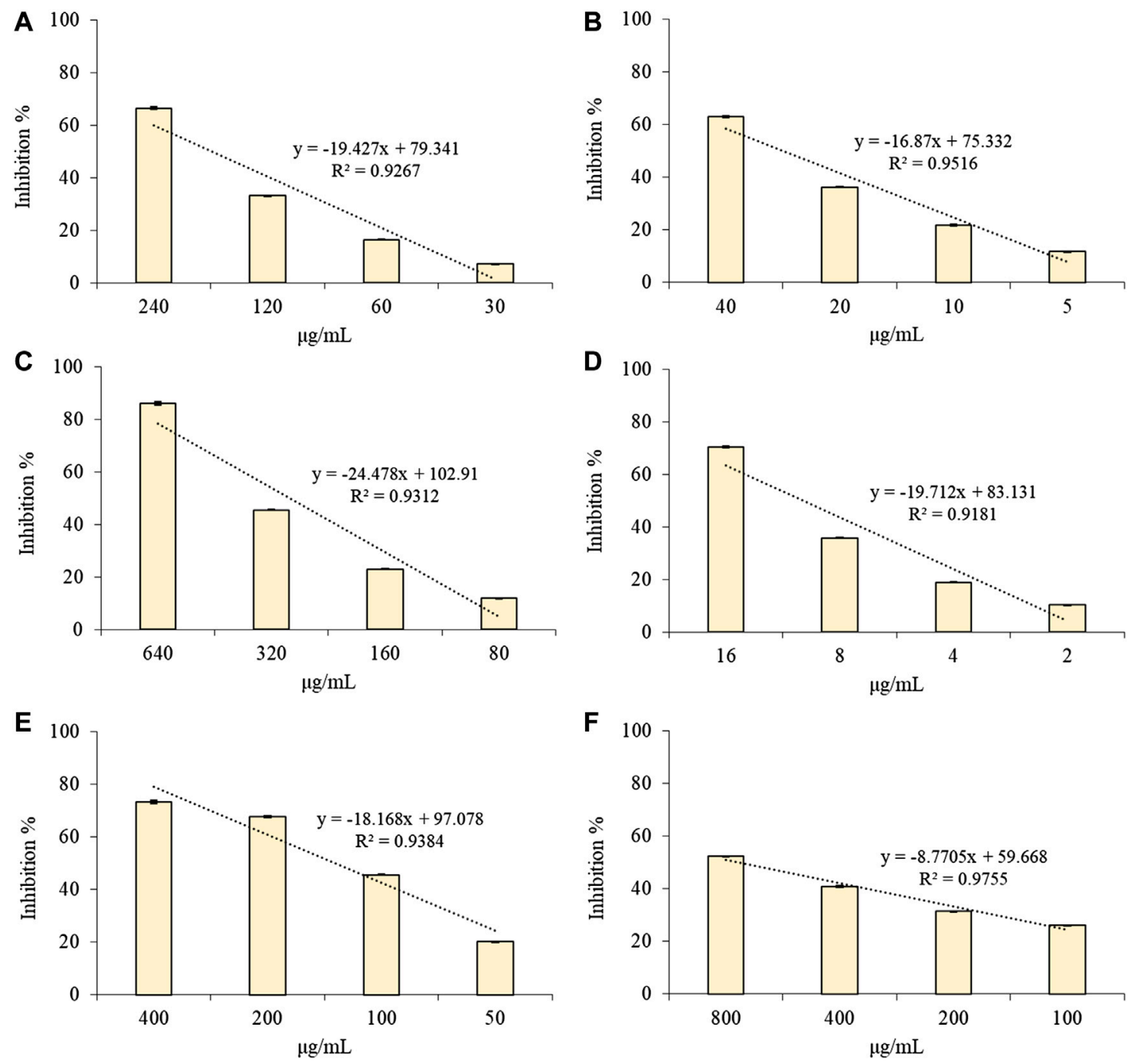

FIGURE 2 | Antioxidant and free radical-scavenging activity of several concentrations of CLJ towards DPPH (A); TEAC (B); FRAP (C); ORAC (D); Iron-chelating activity $\mathbf{( E )}$ and $\beta$-carotene bleaching $\mathbf{( F )}$ assay. Results were expressed as mean inhibition percentage \pm standard deviation of three independent experiments $(n=3)$.

CLJ showed, also in this case, a strong anti-inflammatory activity $(64.41 \%$ at the highest concentration corresponding to $\sim 0.5 \mu \mathrm{l}$ of CLJ) with a statistically significant $(p<0.01)$ and dosedependent behavior $\left(R^{2}=0.9936\right)$ with respect to the positive control diclofenac sodium that, at the highest concentration tested $(80 \mu \mathrm{g} / \mathrm{ml})$, showed an anti-tryptic activity of $78.48 \%$ (Figure $3 B$ ).

The $\mathrm{IC}_{50}$ values with the respective C.L. of CLJ in comparison with the positive control (diclofenac sodium) were reported for both anti-inflammatory assays in Table 2 .

After this preliminary screening of the antioxidant and antiinflammatory activity by cell-free tests, cell-based assays were caried out to deepen investigate the CLJ behavior, which did not interfere, also as pure juice, with the cell viability (data not shown).

The antioxidant results were confirmed by the erythrocytesbased assay, which allowed us to investigate the free-radical scavenging activity of CLJ against the $\mathrm{H}_{2} \mathrm{O}_{2}$-induced intracellular ROS.
In fact, as can be seen from Figure 4A, CLJ showed, also in this case, a strong and dose-dependent $\left(R^{2}=0.9776\right)$ antioxidant activity (inhibition $\%=14.53-59.40$ ) with an $\mathrm{IC}_{50}$ value equal to $79.78 \mu \mathrm{g} / \mathrm{ml}$ (corresponding to $\sim 0.08 \mu \mathrm{l}$ of CLJ). As previously observed in the cell-free assays, a statistically significant difference $(p<0.01)$ was found between the behavior of CLJ and the positive control (trolox). However, the reference compound showed, at a concentration equal to $50 \mu \mathrm{g} / \mathrm{ml}$, an inhibition of the $\mathrm{H}_{2} \mathrm{O}_{2}$-induced intracellular ROS of $68.92 \%$, with an $\mathrm{IC}_{50}$ equal to about half of the CLJ $(34.56 \mu \mathrm{g} / \mathrm{ml}$, C.L. 28.69-41.62), flattening the difference found in cell-free tests and validating further the antioxidant and free-radical scavenging power of CLJ.

The anti-inflammatory activity of CLJ was evaluated firstly as erythrocyte membrane stabilizer in the heat-induced hemolysis test and then monitoring the IL- 6 and TNF- $\alpha$ release after LPSinduced inflammation on PBMC. 
TABLE 2 | In vitro antioxidant and anti-inflammatory activity of C. lumia juice (CLJ) in comparison with reference compounds.

\begin{tabular}{lcc} 
Assay & CLJ & Reference compound \\
\hline Antioxidant activity & & \\
TEAC & $26.26(21.28-32.65)^{\star}$ & $2.92(1.82-4.40)$ \\
ORAC & $10.22(8.47-12.19)^{\star}$ & $0.67(0.33-1.22)$ \\
$\quad \begin{array}{l}\text {-carotene bleaching } \\
\text { Iron-chelating activity }\end{array}$ & $70.80(47.06-106.71)^{\star}$ & $0.21(0.11-0.36)$ \\
FRAP & $286.20(237.11-345.15)^{\star}$ & $6.58(5.20-8.08)$ \\
DPPH & $160.81(137.04-194.26)^{\star}$ & $3.75(1.71-7.59)$ \\
Anti-inflammatory activity & $3.87(1.18-5.45)$ \\
BSA denaturation & $1457.10(1242.32-1709.25)^{\star}$ & $39.21(32.09-47.89)$ \\
assay & & \\
Anti-protease activity & $253.22(186.02-345.15)^{*}$ & $33.48(28.29-39.63)$
\end{tabular}

*Trolox for TEAC, ORAC, FRAP and DPPH assays, BHT for $\beta$-carotene bleaching assay, EDTA for iron-chelating activity. Diclofenac sodium for bovine serum albumin denaturation assay and anti-protease activity. ${ }^{*} \mathrm{p}<0.01$. Results were expressed as halfinhibitory concentration $\left(I C_{50} \mu \mathrm{g} / \mathrm{ml}\right)$ with confident limits (C.L.) at $95 \%$.

The inhibition percentages of the heat-induced hemolysis of red blood cells at different concentrations of CLJ $(200-800 \mu \mathrm{g} / \mathrm{ml})$ are shown in Figure 4B. Although CLJ shows, also in this case, a dose-dependent behavior $\left(R^{2}=0.9932\right)$, it inhibits hemolysis, as pure juice, by a maximum of $15.95 \%$, not allowing to calculate an $\mathrm{IC}_{50}$. However, it should be noted that also the positive control, diclofenac sodium, a well-known anti-inflammatory drug, shows a weak activity in this test, showing an $\mathrm{IC}_{50}$ equal to $128.74 \mu \mathrm{g} / \mathrm{ml}$ (C.L. 105.78-156.70).

The second experimental model based on PBMC allowed us to gain greater insight into the potential anti-inflammatory activity of CLJ, also corroborating what was previously observed with the cell-free tests. Figures 4C,D show the results of the IL-6 and TNF- $\alpha$ release, respectively after the LPS-induced inflammation on PBMC model. CLJ showed not only a dose-dependent behavior $\left(R^{2}=0.9999\right)$ but it decreased significantly $(p<0.01)$ the IL- 6 release by PBMC with respect to the negative control. Moreover, no statistically significant difference was found between the highest concentration of CLJ tested $(1 \mathrm{mg} / \mathrm{ml}$ corresponding to $\sim 1 \mu \mathrm{l}$ of CLJ) and the positive control (diclofenac sodium $50 \mu \mathrm{g} / \mathrm{ml}$ ). The strong antioxidant activity of CLJ has been highlighted even more clearly by the analysis of the TNF- $\alpha$ release by PBMC (Figure 4D). CLJ decreased significantly $(p<0.01)$ the TNF- $\alpha$ release in comparison with the negative control at all concentrations tested (from 1.92 folds at the highest concentration to 1.24 folds at lowest concentration) with a dose-dependent behavior $\left(R^{2}=0.9915\right)$.

These results, even if significantly different $(p<0.01)$ with respect to the diclofenac sodium $50 \mu \mathrm{g} / \mathrm{ml}$, which showed the strongest inhibition of the TNF- $\alpha$ release (3.21 folds with respect to the negative control), show how CLJ, simply a food, is able to exert a strong anti-inflammatory activity even in a cellular model at very low concentrations, which correspond to very few microliters of juice.

\section{Anti-angiogenic Properties}

The CAM model was used as in vivo model to assess the effects of CLJ on angiogenesis. As it is reported in Figure 5A, the inhibitory effects on the neovascularization of the CAMs expressed as inhibition percentage (\%) vs negative control $(100 \%$ of neovascularization), ranged from 35.04 to $77.39 \%$ in the concentration range tested $(90-700 \mu \mathrm{g} / \mathrm{ml})$. The antiangiogenic activity of the highest concentration of CLJ $(77.39 \%)$ was comparable with that of the reference standard retinoic acid (76.19\%). Indeed, no statistically significant difference was found between the highest concentration of CLJ $(700 \mu \mathrm{g} / \mathrm{ml})$ and the positive control (retinoic acid, $10 \mu \mathrm{g} / \mathrm{ml}$ ) (Figure 5A). Conversely, the lower CLJ concentrations $(90-350 \mu \mathrm{g} / \mathrm{ml})$ showed a statistically significant difference with respect to the positive control, showing lowest and dosedependent $\left(R^{2}=0.9882\right)$ inhibitory activities (Figure 5A). The $\mathrm{IC}_{50}$ value of CLJ with the respective C.L. at 95\% was also calculated highlighting a very interesting results $(199.39 \mu \mathrm{g} / \mathrm{ml}$, 155.62-255.47) considering, above all, that this concentration corresponds to a few microliters of pure CLJ $(\sim 0.20 \mu \mathrm{l})$ (Figure 5A).

In Figure 5B representative microscopic images of the CAMs after treatment with the reference compound (retinoic acid, $10 \mu \mathrm{g} / \mathrm{ml}$ ) (a), CLJ samples (b-e) and negative control (deionized water) (f) are reported. CAMs of control eggs showed the presence of a clear vascular network with large vessels (Figure 5F). Conversely, in the CAMs treated with both retinoic acid and CLJ sample (a-e), an evident decrease of the blood vessel branch points was found. Indeed, the vessels

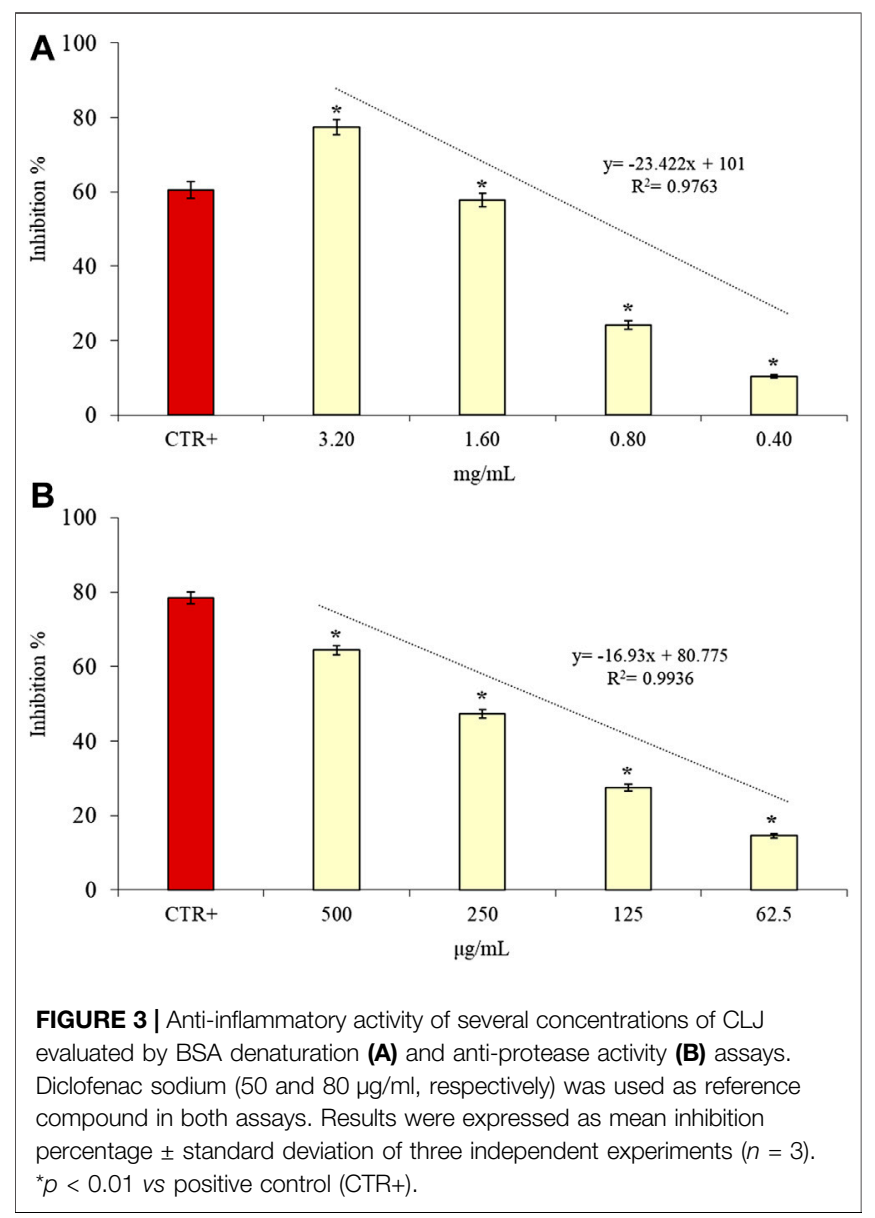



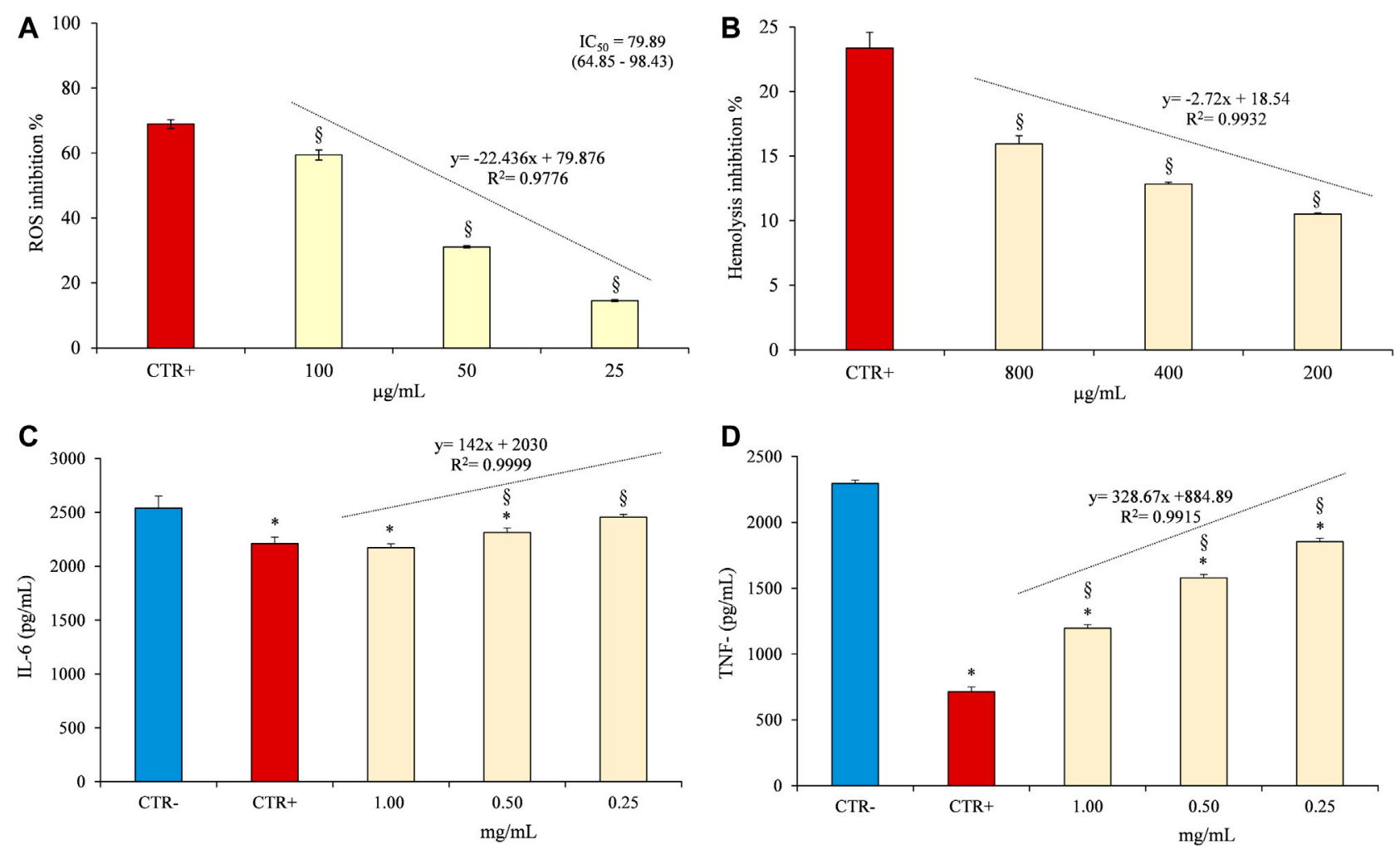

FIGURE 4 | Evaluation of antioxidant and anti-inflammatory activity of CLJ by cell-based assays carried out on erythrocytes (A,B) and PBMC (C,D). (A) Heatinduced hemolysis, diclofenac sodium $50 \mu \mathrm{g} / \mathrm{ml}$ was used as positive control (CTR+); (B) Antioxidant activity against intracellular ROS, trolox 50 $\mu \mathrm{g} / \mathrm{ml}$ was used as positive control (CTR+); (C,D) IL-6 and TNF- $\alpha$ release by PBMC after LPS-induced inflammation, diclofenac sodium $50 \mu \mathrm{g} / \mathrm{ml}$ was used as positive control (CTR+) whereas cell medium culture containing $0.1 \%$ DMSO was used as negative control (CTR-). * $p<0.001$ vs CTR-; ${ }^{\circledR} p<0.001$ vs CTR+.

density is correlated to the blood supply to the standardized area taken into account, whereas it is inversely correlated to the inhibition degree.

Danio rerio known as zebrafish is an ideal experimental model to assess the angiogenic response of test samples and to identify any side effects including toxicity.

As a marker of vessel growth, the EAP activity of vascular endothelial cells released from treated embryos was quantified. Results of CLJ activity on EAP, expressed as inhibition percentage with respect to the negative control (100\% of EAP activity), are reported in Figure 6.

CLJ samples $(125-500 \mu \mathrm{g} / \mathrm{ml}$ corresponding to $0.13-0.51 \mu \mathrm{l})$ showed a strong and dose-dependent $\left(R^{2}=0.9385\right)$ antiangiogenic response reducing significantly $(p<0.01)$ the EAP activity in zebrafish embryos in comparison with the positive control $(2-\mathrm{ME}, 30 \mu \mathrm{g} / \mathrm{ml})$. In particular the highest concentration of CLJ tested showed the strongest (63.37\%) and statistically significant $(p<0.01)$ anti-angiogenic activity with respect to the reference compound 2-ME (52.0\%) without altering survival or inducing malformation to the zebrafish embryos (data not shown).

\section{DISCUSSIONS}

This is the first study, which investigates the polyphenol profile, the ascorbic acid content as well as the antioxidant, anti- inflammatory and anti-angiogenic properties of Citrus lumia juice. However, several researches are available on the characterization and biological activities of the juices of different Citrus species, which allow to critically discuss what it was observed in the present study, also correlating it to the different classes of bioactive compounds identified.

Citrus juices, in particular the hand-squeezed (raw), are one of the main sources of nutrients as well as of secondary metabolites in a standard balanced diet. A part ascorbic acid, one of the main groups of compounds responsible for the health effects of Citrus juices are polyphenols with special reference to phenolic acids and flavonoids (Barreca et al., 2020). According to our results, flavanones and flavones as well as flavonols, which derived from the flavanones following hydroxylation in 3-position, are generally the most abundant classes of the flavonoid pattern of Citrus juices, occurring generally in their glycosylated forms (Barreca et al., 2020). As demonstrated in this study, the most common flavones identified in Citrus species are the glycosylated forms of luteolin, apigenin and diosmetin (Barreca et al., 2020). Flavones and flavanones showed remarkable antioxidant activity, not only acting as a free radical scavenger, but also indirectly modulating the cellular defenses via the NF-E2related factor 2-antioxidant responsive element (Nrf2-ARE) pathway, which regulates the expression of several antioxidant 


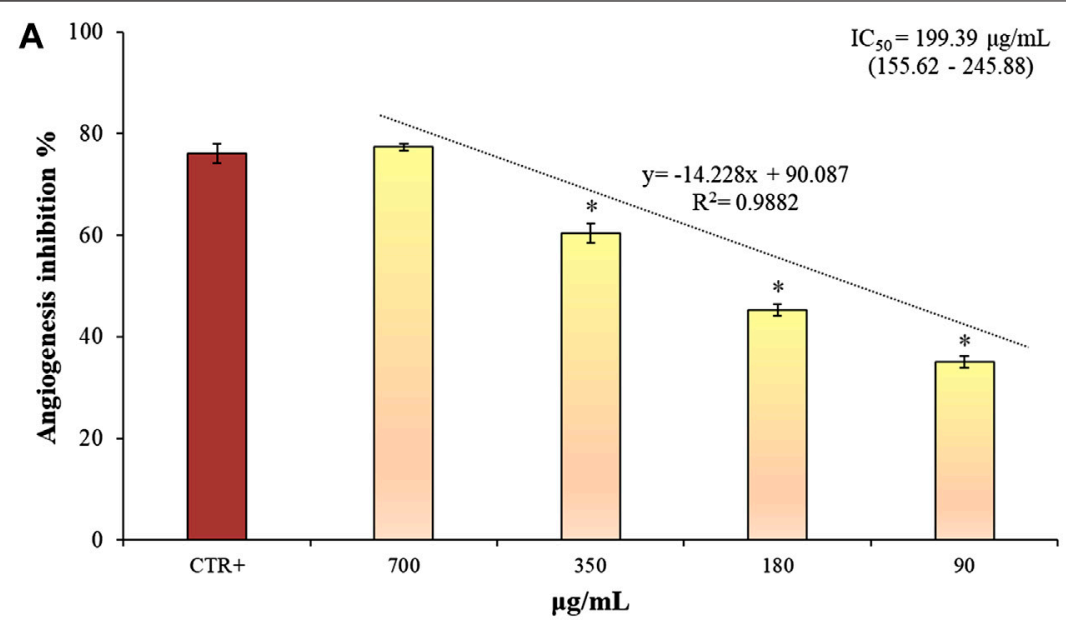

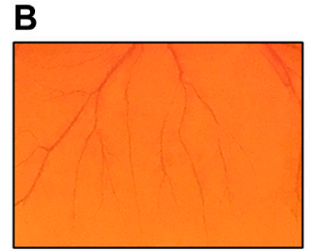

(a)

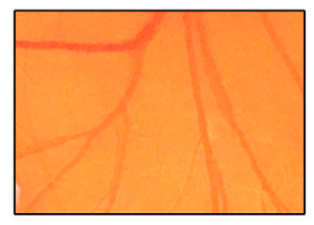

(d)

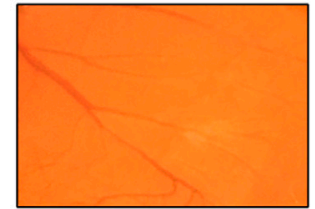

(b)

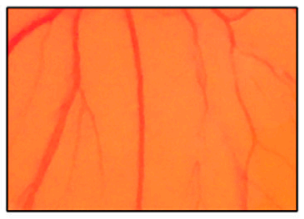

(e)

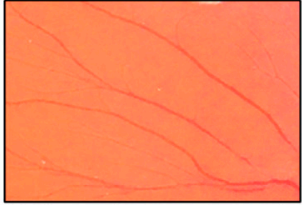

(c)

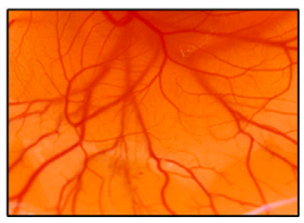

(f)

FIGURE 5 | Anti-angiogenic properties of several concentrations of CLJ evaluated by CAM assay (A). In (B), representative microscopic images of the CAMs after treatment with the reference compound (retinoic acid, $10 \mu \mathrm{g} / \mathrm{ml}$ ) (A), 700-90 $\mu \mathrm{g} / \mathrm{ml} \mathrm{CLJ} \mathrm{samples} \mathrm{(B-E)} \mathrm{and} \mathrm{negative} \mathrm{control} \mathrm{(deionized} \mathrm{water)} \mathrm{(F)} \mathrm{are} \mathrm{reported.} \mathrm{Results}$ were expressed as mean inhibition percentage \pm standard deviation of three independent experiments $(n=5)$. ${ }^{*} p<0.01 \mathrm{vs}$ positive control (CTR +$)$ retinoic acid $10 \mu \mathrm{g} / \mathrm{ml}$.

genes such as heme oxygenase 1 (HO-1), glutathione peroxidase (GPX), and thioredoxin (TXN) (Barreca et al., 2017).

Moreover, they show promising anticancer activity because they are able to decrease the proliferative growth, modulate metabolic pathways and key enzymes (i.e. protein kinase, phosphodiesterase, lipoxygenase, cyclooxygenase, and phospholipase), arrest the cell cycle inducing apoptotic events, revert the multidrug resistance and inhibit the angiogenesis (Barreca et al., 2020).

Regarding flavonols, certainly the most investigated is quercetin. Quercetin and kaempferol derivatives represent the most abundant flavonols in CLJ.

Quercetin has several health properties such as blood pressurelowering effects, antioxidant activity, inhibitory activity on angiotensinconverting enzyme (ACE), enhancing the endothelium function, decreasing the coronary heart disease incidence by attenuating the expression of metalloproteinase 1 and by interfering with the accumulation of atheromatous plaques (Shahidi and Yeo, 2018).
However, in light of our study, what is even more interesting is that quercetin suppress the cyclooxygenase-2 (COX-2) expression in human breast cancer cells by specifically targeting the p300 signaling pathway. COX-2 is an inducible enzyme, which plays a critical role in several patho-physiological events including inflammation, atherosclerosis, tissue injury, angiogenesis and tumorigenesis, up-regulating different pathways such as estimated glomerular filtration rate (eGFR), phosphoinositide 3-kinase (PI3k) and extracellular signalregulated protein kinase (Erk1/2) signaling (Xiao et al., 2011).

Considering this, flavonoids play a pivotal role in the inhibition of the onset and development of inflammatory diseases.

Another class of polyphenols, which show remarkable antioxidant, anti-inflammatory and anti-carcinogenic activity are the phenolic acids.

Among them, hydroxycinnamic acids, according to our results, are the most abundant in plants. The main representatives are coumaric, caffeic, ferulic, and sinapic acids and their derivatives, although they are usually found 


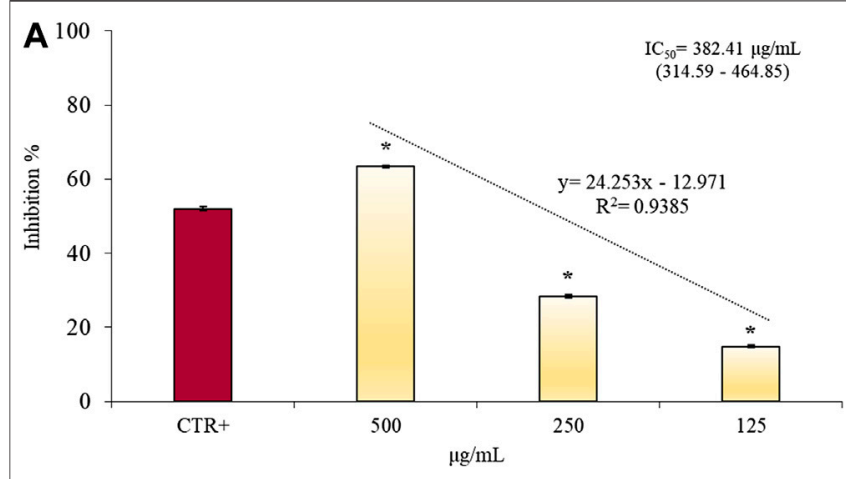

B

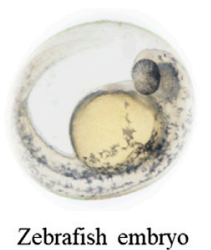

FIGURE 6 | Anti-angiogenic properties of several concentrations of CLJ (125-500 $\mu \mathrm{g} / \mathrm{ml}$ ) evaluated by EAP activity of vascular endothelial cells released from treated zebrafish embryos (A). (B) shows a microscopic image of Zebrafish embryo (magnification 20x). Results were expressed as mean inhibition percentage \pm standard deviation of three independent experiments $(n=5)$. ${ }^{*} p<0.01$ vs positive control (CTR+) 2-methylestradiol $30 \mu \mathrm{g} / \mathrm{ml}$.

as glycosylated derivatives or esters of quinic, shikimic and tartaric acids (Číž et al., 2020). The anti-carcinogenic potential of different phenolic acids has been investigated in several cell lines showing the ability of these compounds to influence the cell cycle, invasion and apoptotic behavior, inducing the expression of several tumor-suppressing proteins such as $\mathrm{p} 53$, phosphatase and tensin homolog (PTEN), p21, and p27. The anti-inflammatory activity of hydroxycinnamic acids is well known thanks to various studies carried out both in vitro and in vivo, by which it has been demonstrated that these compounds act predominantly by decreasing the expression of inflammatory mediators such as the IL-6, IL-1 and TNF- $\alpha$ (Shahidi and Yeo, 2018) as well as by decreasing the expression of nuclear factor kappa-light-chain-enhancer of activated B cells (NF-kB) p65, that recently has been correlated to the angiogenesis process by regulating key angiogenesis factors such as vascular endothelial growth factor (VEGF), transforming growth factor beta (TGF- $\beta$ ), IL-6, and TNF- $\alpha$. Moreover, the inflammatory cytokines IL- 6 and TNF- $\alpha$ are also well-recognized pro-angiogenic factors, which can accelerate the angiogenesis events inducing the vascular remodeling (Cao et al., 2016).

Moreover, it has been demonstrated that caffeic acid induces DNA oxidation of cancer cells and reduces tumor cell angiogenesis by blocking signal transducer and activator of transcription (STAT) proteins and suppressing the collagen IV metalloproteases MMP2 and MMP-9 (Espíndola et al., 2019).
However, a single bioactive compound, even if used at high concentrations, could not be sufficient in preventing or treating inflammatory diseases because several different pathways are involved in diseases progression (Cirmi et al., 2017). Therefore, the employment of plant complexes, sources of a wide range of bioactive compounds, which show additive and/ or synergistic activity together with the simultaneous modulation of different intracellular pathways and cellular targets, represents the best choice.

One of the main issues against the clinical employment of polyphenols or plant complex rich in these bioactive compounds in anti-inflammatory therapy remains always their low bioavailability, although recent in vivo research and clinical trials show evidence to support their use (Hyson, 2015).

It has been demonstrated, for example, that pure (100\%) fruit juice intake increases antioxidant status within $1 \mathrm{~h}$ after consumption, and that the effect may be sustained for several hours depending on the volume and type of juice, subject characteristics and several other unknown factors (Hyson, 2015). Remaining within the Citrus genus, orange juice exhibits a maximal antioxidant effect within $30 \mathrm{~min}$ of intake and induces a statistically significant decrease in ROS generation/oxidative stress in human plasma, sustained for $90 \mathrm{~min}$. Moreover, since the Citrus fruits are very rich in ascorbic acid, the dietary intake of their juices was associated with an increase of the antioxidant status comparable to vitamin C supplementation (Hyson, 2015). Orange juice exerted antioxidant and anti-inflammatory properties at cellular and molecular level from 1 to $5 \mathrm{~h}$ after consumption and it was associated with a significant decrease of diastolic blood pressure compared to placebo and to hesperidin-enriched drink, suggesting a pivotal role for this flavanone in mediating vascular reactivity. Moreover, it has been observed that the intake of a mixed juice from three red orange varieties (Tarocco, Sanguinelllo, and Moro) in humans decrease significantly the C-reactive protein, IL-6, and TNF- $\alpha$ levels after 1 week of juice intake (Hyson, 2015).

A limited number of reports exists on the bioavailability of bioactive compounds in humans associated with Citrus juice intake. Franke et al. (2005) found that an intake of about $250 \mathrm{~mL} /$ day of fresh orange juice increases significantly the Vitamin $C(+59 \%)$ and flavanones hesperetin and naringenin (512\% and $874 \%$ respectively) concentrations after three weeks. The ascorbic acid content of CLJ $(352 \mathrm{mg} / \mathrm{kg})$ is close to that reported in the U.S. Department of Agriculture (USDA) food composition database (USDA, 2020b), with ascorbic acid content in Citrus raw juice, which vary between 300 and $500 \mathrm{mg} / \mathrm{kg}$.

Ascorbic acid is well-known to alter the metabolic activity of endothelial cells by decreasing the ATP levels. This prevents cell proliferation and migration counteracting new blood vessel formation. However, this ability of ascorbic acid seems only secondary to the main mechanism involved into the antiangiogenic effects of this molecule. Ascorbic acid is able to inhibit at high doses the nitric oxide (NO) release in endothelial cells, the key stimulus for new blood vessel formation, by changing the oxidative-reduction status within 
the cells and decreasing the $\mathrm{NO}$ availability through the formation of peroxynitrite (Mikirova et al., 2008).

As a result, a plant complex such as the Citrus juice, with a high content of phenolic acids, flavonoids and ascorbic acid with promising antioxidant, anti-inflammatory and anti-angiogenic properties could be an ideal candidate for the development of anti-cancer drugs (Ngoua-Meye-Misso et al., 2018).

The present study consisted of the phytochemical investigation, antioxidant, anti-inflammatory and antiangiogenic activities of CLJ. In addition to the antioxidant effects, it showed a very strong anti-inflammatory activity compared to that of the reference drug, diclofenac sodium by inhibition of the protein denaturation (BSA) and of the protease activity. It is a well-known that denaturation of tissue proteins leads to inflammatory diseases and that the production of auto-antigens may be due to the denaturation of proteins in vivo (Ngoua-Meye-Misso et al., 2018).

Moreover, to deepen the antioxidant and anti-inflammatory activity of CLJ, two cell-based model were used (erythrocytes and PBMC). This allowed to investigate the interactions between CLJ and the functionally complete cellular enzyme patterns as well as cell membranes, providing more biological relevance to the present study. Erythrocytes are a relevant human cell model in the investigation of the antioxidant protection of natural compounds against oxidative stress as well as to test cell-permeating antioxidants, allowing an easy diffusion also of the glycosylated molecules by the glucose transport protein (GLUT1) (Widén et al., 2012). Moreover, the erythrocytes cell membrane is similar to the lysosomal one and its stabilization may delay or inhibit the lysis, counteracting the release of the cytoplasmatic content and decreasing consequently the tissue damage and the trigger of the inflammatory cascades (Gunathilake et al., 2018).

PBMC physiologically contribute to the tissue self-healing mechanisms. They are able to release cytokines that direct resident stem cells towards tissue regenerative processes and mainly perform three functions: (i) induce the formation of new blood vessels in the tissue to be regenerated (angiogenesis), (ii) modulate inflammation by inducing the reparative phase of the macrophage and (iii) can differentiate and intervene directly in the regenerative process (Beer et al., 2016).

During inflammation, they release IL- 6 and TNF- $\alpha$, proinflammatory cytokines, which play a pivotal role in different steps of several chronic inflammatory diseases. IL- 6 regulates the growth and differentiation of various cell types that play a key role in the immune and hematopoietic system. It is also an important inducer of acute phase reactions in response to inflammation or tissue damage. TNF- $\alpha$ has anti-cancer and growth regulatory activities showing selectivity for tumor cells and carrying out pro-angiogenic activity. It also has immunomodulatory and pro-inflammatory activities by inducing the production of other inflammatory mediators such as IL-1, IL-6, prostaglandins, platelet activating factor (PAF), etc. (Muñoz and Costa, 2013).

CLJ showed a strong antioxidant and anti-inflammatory activity also in these two cell-based models, corroborating what observed in preliminary cell-free assays as well as the results of previous studies, which highlighted the strong antioxidant and anti-inflammatory activity of Citrus juices in inhibiting in particular the IL- 6 and TNF- $\alpha$ release that, other than inflammatory markers, are recognized as key proangiogenic factors (Cao et al., 2016). This is even more true since the results of anti-inflammatory activity are also reflected in the anti-angiogenic activity observed in vivo. Indeed, CLJ showed strong and dose-dependent antiangiogenic activity, by inhibiting the blood vessel formation on CAMs and by decreasing the EAP on zebrafish embryos. Moreover, within the concentration range tested, no cell viability alteration or dead or malformed embryos were recorded, indicating that the antioxidant, anti-inflammatory and anti-angiogenic effect observed was not due to the toxicity of CLJ.

\section{CONCLUSIONS}

In conclusion, this study provides evidences that C. lumia juice have antioxidant, anti-inflammatory and anti-angiogenic properties. These activities are certainly due to the marked presence of phenolic acids, flavonoids and ascorbic acid, phytochemicals well-known to exerts these health effects in vitro and in vivo. Certainly, this is the first study, which sheds light on the main biological activities attributable to this plant complex, but further in vitro and in vivo studies are necessary to deepen the molecular mechanisms and cellular targets involved in the health activities found that could justify the use of CLJ as a safe prevention strategy for inflammatorybased diseases correlated to angiogenesis.

Another limitation of our study is certainly the low availability of C. lumia fruits, but as it was done previously for other fruits belonging to the Citrus genus, the research can shed light on new interesting species from a health point of view, paving the way also to an increase in crop production through the establishment of experimental fields.

\section{DATA AVAILABILITY STATEMENT}

The raw data supporting the conclusions of this manuscript will be made available by the authors, without undue reservation, to any qualified researcher.

\section{AUTHOR CONTRIBUTIONS}

AS and DT were involved in conception and design, acquisition of data, analysis and interpretation of data. All authors performed the experiments, contribute to draft the manuscript and approved the submitted version.

\section{SUPPLEMENTARY MATERIAL}

The Supplementary Material for this article can be found online at: https://www.frontiersin.org/articles/10.3389/fphar.2020.593506/ full\#supplementary-material. 


\section{REFERENCES}

Barreca, D., Laganà, G., Leuzzi, U., Smeriglio, A., Trombetta, D., and Bellocco, E. (2016). Evaluation of the nutraceutical, antioxidant and cytoprotective properties of ripe pistachio (Pistachia vera L. variety Bronte) hulls. Food Chem. 196, 493-502. doi:10.1016/j.foodchem.2015.09.077

Barreca, D., Gattuso, G., Bellocco, E., Calderaro, A., Trombetta, D., Smeriglio, A., et al. (2017). Flavanones: citrus phytochemical with health-promoting properties. Biofactors 43 (4), 495-506. doi:10.1002/biof.1363

Barreca, D., Mandalari, G., Calderaro, A., Smeriglio, A., Trombetta, D., Felice, M. R., et al. (2020). Citrus flavones: an update on sources, biological functions, and health promoting properties. Plants 9 (3), 288-310. doi:10.3390/plants9030288

Bazzicalupo, M., Burlando, B., Denaro, M., Barreca, D., Trombetta, D., Smeriglio, A., et al. (2019). Polyphenol characterization and skin-preserving properties of hydroalcoholic flower extract from Himantoglossum robertianum (orchidaceae). Plants 8 (11), 502-515. doi:10.3390/plants8110502

Beer, L., Mildner, M., Gyöngyösi, M., and Ankersmit, H. J. (2016). Peripheral blood mononuclear cell secretome for tissue repair. Apoptosis. 21 (12), 1336-1353. doi:10.1007/s10495-016-1292-8

Cao, W., Hu, C., Wu, L., Xu, L., and Jiang, W. (2016). Rosmarinic acid inhibits inflammation and angiogenesis of hepatocellular carcinoma by suppression of NF- $\mathrm{BB}$ signaling in H22 tumor-bearing mice. J. Pharmacol. Sci. 132 (2), 131-137. doi:10.1016/j.jphs.2016.09.003

Cirmi, S., Maugeri, A., Ferlazzo, N., Gangemi, S., Calapai, G., Schumacher, U., and Navarra, M. (2017). Anticancer potential of citrus juices and their extracts: a systematic review of both preclinical and clinical studies. Front. Pharmacol. 8, 420-430. doi:10.3389/fphar.2017.00420

Číž, M., Dvořáková, A., Skočková, V., and Kubala, L. (2020). The role of dietary phenolic compounds in epigenetic modulation involved in inflammatory processes. Antioxidants 9 (8), 691-710. doi:10.3390/antiox9080691

Espíndola, K. M. M., Ferreira, R. G., Narvaez, L. E. M., Rosario, A. C. R. S., Da Silva, A. H. M., Silva, A. G. B., et al. (2019). Chemical and pharmacological aspects of caffeic acid and its activity in hepatocarcinoma. Front Oncol. 9, 541-551. doi:10. 3389/fonc.2019.00541

Franke, A. A., Cooney, R. V., Henning, S. M., and Custer, L. J. (2005). Bioavailability and antioxidant effects of orange juice components in humans. J. Agric. Food Chem. 53 (13), 5170-5178. doi:10.1021/jf050054y

Gunathilake, K. D. P. P., Ranaweera, K. K. D. S., and Rupasinghe, H. P. V. (2018). In Vitro anti-inflammatory properties of selected green leafy vegetables. Biomedicines 6 (4), 107. doi:10.3390/biomedicines6040107

Hougee, S., Sanders, A., Faber, J., Graus, Y. M., van den Berg, W. B., Garssen, J., et al. (2005). Decreased pro-inflammatory cytokine production by LPSstimulated PBMC upon in vitro incubation with the flavonoids apigenin, luteolin or chrysin, due to selective elimination of monocytes/macrophages. Biochem. Pharmacol. 69 (2), 241-248. doi:10.1016/j.bcp.2004.10.002

Hyson, D. A. (2015). A review and critical analysis of the scientific literature related to $100 \%$ fruit juice and human health. Adv. Nutr. 6 (1), 37-51. doi:10.3945/an.114.005728

Iannuzzi, A. M., Camero, C. M., D’Ambola, M., D’Angelo, V., Amira, S., Bader, A., et al. (2019). Antiangogenic iridoids from Stachys ocymastrum and Premna resinosa. Planta Med. 85, 1034-1039. doi:10.1055/a-0889-0412

Mazurek, A., and Jamroz, J. (2015). Precision of dehydroascorbic acid quantitation with the use of the subtraction method - validation of HPLC-DAD method for determination of total vitamin $\mathrm{C}$ in food. Food Chem. 173, 543-550. doi:10. 1016/j.foodchem.2014.10.065

Mikirova, N. A., Ichim, T. E., and Riordan, N. H. (2008). Anti-angiogenic effect of high doses of ascorbic acid. J. Transl. Med. 6, 50-60. doi:10.1186/1479-5876-6-50

Monforte, M. T., Smeriglio, A., Germanò, M. P., Pergolizzi, S., Circosta, C., and Galati, E. M. (2018). Evaluation of antioxidant, antiinflammatory, and gastroprotective properties of Rubus fruticosus L. fruit juice. Phytoter. Res. 32 (7), 1404-1414. doi:10.1002/ptr.6078

Muñoz, A., and Costa, M. (2013). Nutritionally mediated oxidative stress and inflammation. Oxid. Med. Cell. Longev. 2013, 1-11. doi:10.1155/2013/610950

Ngoua-Meye-Misso, R., De La Croix Ndong, J., Sima-Obiang, C., Ondo, P. J., Ndon-Atome, G. R., Abessolo, F. O., et al. (2018). Phytochemical studies, antiangiogenic, antiinflammatory and antioxidant activities of Scyphocephalium ochocoa Warb. (Myristicaceae), medicinal plant from Gabon. Clin. Phytosci. 4, 15-27. doi:10.1186/s40816-018-0078-7
Oyedapo, O. O., and Famurewa, A. J. (1995). Antiprotease and membrane stabilizing activities of extracts of Fagara zanthoxyloides, Olax subscorpioides and Tetrapeura tetraptera. Int. J. Pharm. 33 (1), 65-69. doi:10.3109/13880209509088150

Rossi, T., Gallo, C., Bassani, B., Canali, S., Albini, A., and Bruno, A. (2014). Drink your prevention: beverages with cancer preventive phytochemicals. Pol. Arch. Med. Wewn. 124 (12), 713-722. doi:10.20452/pamw.2560

Saso, L., Valentino, G., Casini, M. L., Grippa, E., Gatto, M. T., Leone, M. G., et al. (2001). Inhibition of Heat-induced denaturation of albumin by nonsteroidal anti-inflammato drugs (NSAIDs): pharmacological implications. Arch Pharm. Res. (Seoul) 24 (2), 150-158. doi:10.1007/bf02976483

Shahidi, F., and Yeo, J. (2018). Bioactivities of phenolics by focusing on suppression of chronic diseases: a review. Int. J. Mol. Sci. 19 (6), 1573-1589. doi:10.3390/ ijms 19061573

Slavin, J. L., and Lloyd, B. (2012) Health benefits of fruits and vegetables. Adv Nutr. 3, 506-516. doi:10.3945/an.112.002154

Smeriglio, A., Denaro, M., Barreca, D., Calderaro, A., Bisignano, C., Ginestra, G., et al. (2017). In vitro evaluation of the antioxidant, cytoprotective, and antimicrobial properties of essential oil from Pistacia vera L. variety bronte hull. Int. J. Mol. Sci. 18 (6), 1212-1224. doi:10.3390/ijms18061212

Smeriglio, A., Alloisio, S., Raimondo, F. M., Denaro, M., Xiao, J., Cornara, L., et al. (2018a). Essential oil of Citrus lumia Risso: phytochemical profile, antioxidant properties and activity on the central nervous system. Food Chem. Toxicol. 119, 407-416. doi:10.1016/j.fct.2017.12.053

Smeriglio, A., Denaro, M., Barreca, D., D’Angelo, V., Germanò, M. P., and Trombetta, D. (2018b). Polyphenolic profile and biological activities of black carrot crude extract (Daucus carota L. ssp. sativus var. atrorubens Alef.) Fitoterapia 124, 49-57. doi:10.1016/j.fitote.2017.10.006

Smeriglio, A., Cornara, L., Denaro, M., Barreca, D., Burlando, B., Xiao, J., et al (2019a). Antioxidant and cytoprotective activities of an ancient Mediterranean citrus (Citrus lumia Risso) albedo extract: microscopic observations and polyphenol characterization. Food Chem. 279, 347-355. doi:10.1016/j.foodchem.2018.11.138

Smeriglio, A., Ragusa, S., Monforte, M. T., D'angelo, V., and Circosta, C. (2019b). Phytochemical analysis and evaluation of antioxidant and antiacetylcholinesterase activities of Euphorbia dendroides L. (Euphorbiaceae) latex. Plant Biosyst. 153 (4), 498-505. doi:10.1080/11263504.2018.1498405

Smeriglio, A., Denaro, M., De Francesco, C., Cornara, L., Barreca, D., Bellocco, E., et al. (2019c). Feijoa fruit peel: micro-morphological features, evaluation of phytochemical profile, and biological properties of its essential oil. Antioxidants 8 (8), 320-336. doi:10.3390/antiox 8080320

United States Department of Agriculture (2020a). Available at: https://www.fas. usda.gov/psdonline/circulars/citrus.pdf (Accessed August 1, 2020).

United States Department of Agriculture (2020b). Available at: https://ods.od.nih gov/pubs/usdandb/VitaminC-Content.pdf (Accessed August 6, 2020).

Smeriglio, A., Bonasera, S., Germanò, M. P., D’Angelo, V., Barreca, D., Denaro, M., et al. (2019d). Opuntia ficus-indica (L.) Mill. fruit as source of betalains with antioxidant, cytoprotective, and anti-angiogenic properties. Phytoter. Res. 33 (5), 1526-1537. doi:10.1002/ptr.6345

Viji, V. and Helen, A. (2008). Inhibition of lipoxygenases and cyclooxygenase-2 enzymes by extracts isolated from Bacopa monniera (L.) Wettst. J. Ethnopharmacol. 118 (2), 305-311. doi:10.1016/j.jep.2008.04.017

Widén, C., Ekholm, A., Coleman, M. D., Renvert, S., and Rumpunen, K. (2012). Erythrocyte antioxidant protection of rose hips (Rosa spp.). Oxid. Med. Cell. Longev. 2012, 1-8. doi:10.1155/2012/621579

Xiao, X., Shi, D., Liu, L., Wang, J., Xie, X., Kang, T., and Deng, W. (2011). Quercetin suppresses cyclooxygenase-2 expression and angiogenesis through inactivation of P300 signalling. PLoS One 6 (8), e22934. doi:10.1371/journal.pone.0022934

Conflict of Interest: The authors declare that the research was conducted in the absence of any commercial or financial relationships that could be construed as a potential conflict of interest.

Copyright (c) 2020 Smeriglio, Denaro, D'Angelo, Germanò and Trombetta. This is an open-access article distributed under the terms of the Creative Commons Attribution License (CC BY). The use, distribution or reproduction in other forums is permitted, provided the original author(s) and the copyright owner(s) are credited and that the original publication in this journal is cited, in accordance with accepted academic practice. No use, distribution or reproduction is permitted which does not comply with these terms. 